
de la persona del ejecutado y del patrimonio en que Tesorería puede hacer efectivo el crédito fiscal. A propósito de un fallo del Juzgado de Colina y su confirmación por la Corte de Apelaciones de Santiago Fernando Ugarte Vial

Trabajo recibido el 3 de julio de 2017 y aprobado el 27 de septiembre de 2017

\title{
Algunas consideraciones en torno al juicio ejecutivo de cobro de impuesto territorial, con especial mención de la persona del ejecutado y del patrimonio en que Tesorería puede hacer efectivo el crédito fiscal. A propósito de un fallo del Juzgado de Colina y su confirmación por la Corte de Apelaciones de Santiago
}

Certain CONSIDERATIONS ON THE PROCEDURE TO ENFORCE COLLECTION OF THE TERRITORIAL TAX, WITH SPECIAL REFERENCE TO THE PERSON OF THE DEFENDANT AND THE PROPERTY AGAINST WHICH THE TREASURY MAY PURSUE PAYMENT. IN RELATION TO A DECISION OF THE COURT OF COLINA, AND ITS CONFIRMATION BY THE COURT OF APPEALS OF SANTIAGO

Fernando UGARTE ViaL*

RESUMEN

Se revisan los fallos de primera y segunda instancia de un juicio ejecutivo de cobro de impuesto territorial, en que Tesorería ejecutó y emplazó al ex propietario de un bien raíz, el que fue rematado y adjudicado a un tercero, extendiéndose la escritura de remate y practicándose su inscripción conservatoria. Después de efectuada la inscripción, compareció en el juicio el verdadero dueño del sitio, promoviendo incidente de nulidad de lo obrado por falta de emplazamiento, el que fundó en el hecho de haberse notificado y requerido de pago a un ex propietario. El incidente fue rechazado en ambas instancias.

\section{ABSTRACT}

The first and second instance rulings of a procedure to enforce collection of the territorial tax are reviewed, in which the Treasury collected taxes against the former owner of a real estate, which was auctioned and awarded to a third party, and in which the auction deeds were issued and registered in the Real Estate Registry in the name of the auctionee. After the registration was performed, the true owner of the real estate appeared before the court, submitting a motion of nullity of the procedure based on the lack of formal summons, founded on the fact that the summons and the request of payment were addressed against the former owner. The motion was rejected in both instances.

\footnotetext{
* Abogado. Licenciado en Ciencias Jurídicas y Sociales de la Universidad de Los Andes, Santiago, Chile. Correo electrónico: fernandougartevial@gmail.com.

Este comentario se enmarca en el contexto de una investigación más amplia, sobre los vicios y errores que suelen producirse en el juicio ejecutivo de cobro de impuesto territorial, en perjuicio de los propietarios de los inmuebles.
} 
Palabras Clave

Impuesto territorial; cobro ejecutivo; venta forzada; compraventa; ejecutado.

KEY WORDS

Territorial tax; judicial collection; forced sale; purchase and sale; collection defendant.

\section{Introducción y contexto}

El juicio ejecutivo de cobro de impuesto territorial comienza cuando la Tesorería General de la República constata la existencia contribuciones impagas, para cuyo cobro se elaboran las "Nóminas de Deudores Morosos", título que sirve de base a la ejecución, según la norma del art. 169 del Código Tributario" A continuación de la nómina, el Tesorero Juez Sustanciador -funcionario de Tesorería- estampa la resolución, en que ordena despachar mandamiento de ejecución y embargo en contra de los deudores individualizados en la nómina antecedente, resolución que hace las veces de auto cabeza de proceso. Si los ejecutados no pagan al ser requeridos, el inmueble se entenderá embargado por el solo ministerio de la ley. Posteriormente, el Tesorero Juez Sustanciador elaborará una Nómina de Segunda Etapa, en que individualizará a los deudores que no hayan regularizado su situación de morosidad, contra quienes continuará la segunda etapa de la ejecución, ante la justicia ordinaria. Esta segunda etapa comienza con una presentación de Tesorería al juez civil, en que pedirá que se pronuncie sobre las excepciones opuestas por los deudores ejecutados, y en caso de no haber excepciones, pedirá al juez que decrete el remate de los inmuebles individualizados en la Nómina de Segunda Etapa, y la ejecución seguirá su curso hasta obtenerse el pago de la obligación por los deudores ejecutados señalados en la nómina. Cabe mencionar, finalmente, que el artículo 25 de la ley 17.235 sobre Impuesto Territorial, señala que son obligados al pago del impuesto tanto los propietarios de los inmuebles como sus ocupantes o meros tenedores.

\section{Resumen del caso}

En juicio ejecutivo de cobro de impuesto territorial, la Tesorería ejecutó y emplazó a don Juan de Dios Alvarado Farías, a fin de obtener el pago compulsivo de las contribuciones morosas de un inmueble compuesto de cinco lotes. El 9 de septiembre de 2013 se llevó a cabo el remate solicitado por la ejecutante, resultando adjudicado dicho sitio a un tercero. Se redujo el acta de remate a escritura pública, la que fue inscrita en el Registro de Propiedad del Conservador respectivo con fecha 4 de agosto de 2014.

\footnotetext{
1 Aunque la ley no lo dice, la cobranza suele iniciarse cuando hay a lo menos cuatro cuotas impagas de impuesto territorial.
} 
Algunas consideraciones en torno al juicio ejecutivo de cobro de impuesto territorial, con especial mención de la persona del ejecutado y del patrimonio en que Tesorería puede hacer efectivo el crédito fiscal. A propósito de un fallo del Juzgado de Colina y su confirmación

El 23 de enero de 2015 compareció en el juicio la sociedad Agrícola Colina Limitada, la verdadera dueña del inmueble a la época en que se había formado la nómina de deudores morosos, promoviendo incidente de nulidad de lo obrado por falta de emplazamiento, el que fundó -en lo que ahora interesa- en que ella era dueña exclusiva del inmueble rematado, desde 1992, no obstante lo cual, se notificó y requirió de pago a un ex propietario, que había sido incluido en la nómina por error. Dijo también que se había enterado de la existencia del juicio el 19 de enero anterior, al hacer gestiones para la venta de los cinco lotes que conformaban el inmueble.

\section{Recepción de la causa a prueba}

Al recibir el incidente a prueba, el tribunal fijó los siguientes hechos pertinentes, sustanciales y controvertidos: " 1 . Efectividad que la incidentista era propietaria del inmueble al momento de practicarse la notificación de la demanda y el requerimiento de pago. 2. Efectividad que la incidentista dio cumplimiento a las normas legales, informando al Servicio de Impuestos Internos sobre el cambio de dominio del inmueble. 3. Efectividad que la incidentista no ha sido notificada de la demanda y de su resolución, ni requerida de pago por un hecho no imputable a su parte. 4 . Fecha en que la incidentista tuvo conocimiento del presente juicio".

\section{Fallos de primer y segundo grado}

El juez de primera instancia² rechazó el incidente de nulidad, argumentando que: i) rematado el inmueble y firme la resolución que ordena extender la escritura de subasta y alzar los gravámenes, ya no se puede declarar la nulidad procesal, por haber concluido el juicio ejecutivo. Ahondando en este argumento, se dice que el incidentista promovió su solicitud cuando el juicio ejecutivo ya había cumplido todos sus efectos, una vez inscrita la propiedad a nombre del subastador y ya satisfecho el crédito fiscal; a continuación y en abono de esta idea, dice el fallo que la subasta sería en realidad una expropiación y no una compraventa, y que bastaría su sola ocurrencia para que opere la traslación del dominio del inmueble al adjudicatario, sirviendo la inscripción conservatoria como una simple "medida de orden, publicidad y para mantener la historia del bien raíz" (considerando 5), y ii) el incidente resultaba extemporáneo, considerando que la inscripción de dominio de los inmuebles figuraba a nombre del adjudicatario en un registro público como el de Propiedad del Conservador de Bienes Raíces, desde agosto de 2014 (c. 6º), y que con la publicación de los

2 Juzgado de Letras de Colina, rol № 1451-2013, 5 de febrero de 2016. 
avisos que señala el artículo 185 del Código Tributario, se habría cumplido "con la publicidad exigida por la ley, la cual tiene por objeto poner en conocimiento de los interesados la subasta, con el fin de que puedan ejercer las acciones $o$ actuaciones que estimen pertinentes" (c. $7^{\circ}$ ).

Apelado el fallo, fue confirmado por la Corte de Apelaciones de Santiago ${ }^{3}$, previa supresión de su quinto considerando. Añadió el tribunal de alzada: "Que si bien es cierto, la nulidad procesal solo puede alegarse 'in limine litis', ello no tiene lugar cuando se invoca la nulidad por falta de emplazamiento, toda vez que en tal caso, el efecto de cosa juzgada de la sentencia definitiva firme solo es aparente", sin perjuicio de lo cual estimó que "de los antecedentes resulta absolutamente claro que el incidente de nulidad procesal se interpuso fuera de la oportunidad que establece el artículo 83 del Código de Procedimiento Civil".

\section{Comentario}

El presente comentario se estructura en base al análisis de las siguientes cuestiones: i) naturaleza de la obligación de pagar el impuesto territorial, ii) patrimonio en que la Tesorería puede hacer efectivo el crédito fiscal, iii) naturaleza de compraventa del remate en pública subasta, iv) en la especie no había falta de emplazamiento, sino inexistencia de relación jurídico-procesal respecto del dueño del inmueble rematado, y v) plazo para reclamar de este vicio.

\subsection{Previo a abordar la cuestión del patrimonio en que Tesorería puede hacer efectivo el crédito fiscal, es necesario examinar la naturaleza de la obligación de pagar el impuesto territorial. Las teorías más difundidas son las siguientes:}

\subsubsection{Obligación que grava directamente al inmueble, sin importar la persona del deudor}

Algunos han entendido que la obligación de pagar el impuesto territorial recaería directamente sobre el inmueble que lo causa, resultando irrelevante la persona del deudor'; dicho en otras palabras, el ejecutado sería el rol o inmueble, sin importar la persona que figure como ejecutada en la nómina de deudores morosos. Esta concepción de la obligación de pagar la contribución territorial ha cundido entre los litigantes e incluso entre los jueces, con consecuencias verdaderamente desastrosas ${ }^{5}$.

3 Corte de Apelaciones de Santiago, rol N³028-2016, 31 de mayo de 2016.

4 ROJAS (2001), pp. 76-77.

5 De entre las resoluciones encontradas en este sentido, pueden verse a modo de ejemplo las dos que siguen: i) "Que, en cuanto a la persona del demandado, hay que considerar que estamos frente al cobro de impuesto territorial, que grava los inmuebles mismos, sin importar el propietario de éstos, 
Algunas consideraciones en torno al juicio ejecutivo de cobro de impuesto territorial, con especial mención de la persona del ejecutado y del patrimonio en que Tesorería puede hacer efectivo el crédito fiscal. A propósito de un fallo del Juzgado de Colina y su confirmación por la Corte de Apelaciones de Santiago

Tratando de la naturaleza de esta obligación, dice Roberto Rojas Retamal que la persona del sujeto pasivo del impuesto, lejos de ser irrelevante, ha sido cuidadosamente regulada en la ley sobre Impuesto Territorial, cuyo artículo 25 distingue claramente entre dos tipos de obligados al pago: de un lado, está el dueño del inmueble y, del otro, están sus ocupantes, a quienes se confiere acción para exigir al propietario que les reembolse lo que hubieren pagado por concepto de impuesto territorial. En los siguientes artículos, la ley regula otros casos especiales, como el del representante legal de una persona jurídica propietaria de un inmueble, el de los comuneros y el de los ocupantes de bienes raíces fiscales, municipales y nacionales de uso público ${ }^{6}$.

Por las razones expuestas - que compartimos-, Rojas descarta que la persona del deudor sea irrelevante y que la obligación recaiga directamente sobre el inmueble ${ }^{7}$. Cabe mencionar, además, que no son concebibles las obligaciones sin un sujeto pasivo determinado, "en blanco" o "por llenar", por decirlo de alguna forma. Además, el Código Civil se encarga de establecer expresamente lo contrario, al definir los derechos personales o de crédito, de los cuales son correlativas las obligaciones, al señalar que son aquellos "que sólo pueden reclamarse de ciertas personas, que por un hecho suyo o por la sola disposición de la ley, han contraído las obligaciones correlativas" (art. 578). Aquí, la frase "ciertas personas" equivale a determinadas personas, como resulta de cotejar la definición citada con la que da el art. 577 del derecho real, diciendo que es "el que tenemos sobre una cosa sin respecto a determinada persona".

\subsubsection{Teoría de la carga real}

Para Alessandri, Somarriva y Vodanovic, esta obligación constituye una verdadera carga real, entendiendo por tal el "gravamen que afecta a una cosa y cuya prestación debe hacerse por el titular activo del derecho real o de la posesión que existe sobre ella"8. Entre las características de las cargas reales, señalan estos autores que, el sujeto activo del derecho real o de la posesión, responde de las deudas en razón de la cosa, pero "sólo hasta el valor del bien que la carga grava, salvo disposición expresa de la ley en contrario" ${ }^{\prime 9}$.

por lo que es un impuesto real" (28 Juzgado Civil de Santiago, rol № 1658-1995, de 19 de enero de 1998), y ii) "Que de acuerdo a la naturaleza jurídica del impuesto territorial, éste persigue la cosa, independiente de quien aparezca como dueño, es decir es una suerte de derecho real" (20 Juzgado Civil de Santiago, rol №35676-2009, de 24 de noviembre de 2010).

6 Rojas (2001), pp. 77-82.

7 Rojas (2001), pp. 80-82.

8 Alessandri, Somarriva y Vodanovic (2001), pp. 111-112.

9 Alessandri, Somarriva y Vodanovic (2001), pp. 111-112. 


\subsubsection{Teoría de la obligación propter rem}

Dice el eminente civilista y juez argentino, Jorge Joaquín Llambías, que las obligaciones propter rem o ambulatorias "se constituyen en función de cierta relación de señorío que tiene una persona indeterminada sobre una cosa determinada. En rigor, no hay indeterminación del sujeto sino ausencia de su individualización, porque ello dependerá del momento de la vida de la obligación en que se la haga valer: según que ello ocurra en tal o cual momento, el acreedor o deudor, será $A, B$ o $X$, quienquiera fuere el poseedor de la cosa con motivo de la cual se ha generado la obligación... el crédito o deuda, nace, subsiste o se extingue, junto con la relación de señorío mencionada"10.

5.1.4 Según se advierte de las palabras del profesor Llambías, la obligación de que venimos tratando es una obligación propter rem, cuyo sujeto pasivo está perfectamente determinado (el dueño o el ocupante del inmueble), aunque no estará individualizado de forma precisa, sino hasta que se exija el cumplimiento de la obligación, lo cual dependerá del momento en que se forme la nómina de deudores morosos, con miras a exigir el pago del impuesto moroso. La naturaleza ambulatoria de la obligación de pagar el impuesto territorial se manifiesta en el hecho de que el propietario actual del inmueble es el obligado al pago del impuesto devengado con anterioridad a que él entrara en dominio de la bien raíz. Al respecto, ha dicho la Corte de Concepción: "1... El sujeto pasivo [del impuesto territorial] es el dueño o el ocupante de la propiedad... 2.- Que en la situación en estudio... el Servicio de Tesorerías inició la cobranza administrativa de tales deudas, emplazando a quien aparecía como dueño en los roles confeccionados por el Servicio de Impuestos Internos... 8.- Que en materia de impuesto territorial el requerimiento judicial debe efectuarse a la persona natural o jurídica que sea la propietaria del inmueble a la fecha del requerimiento... 9.- Que... viene a resultar que las deudas devengadas con anterioridad a la adquisición del dominio deben ser cobradas al o los actuales propietarios, debiendo dirigirse la ejecución en contra de él o ellos y no del anterior dueño..."11.

Sin perjuicio de lo dicho, y como dicen Alessandri, Somarriva y Vodanovic, parte importante de la doctrina es partidaria de suprimir la figura de las cargas reales, para incluirlas derechamente dentro de la categoría de obligaciones propter rem ${ }^{12}$.

5.2. Despejado lo anterior, nos interesa poner de relieve una idea sencilla, pero de fundamental importancia, que suele echarse al olvido tratándose de este

10 Llambías (1983), pp. 22-23.

11 Corte de Apelaciones de Concepción, rol № 519-2005, de 10 de septiembre de 2008.

12 Alessandri, Somarriva y Vodanovic (2001), p. 112. 
juicio especial: al igual que el actor de cualquier juicio ejecutivo, la Tesorería solo puede hacer efectivo el crédito fiscal en el patrimonio del deudor ejecutado, sea el dueño del inmueble o su ocupante, y no en el de terceros ajenos a la relación procesal. Por lo anterior, solo será posible rematar el inmueble que causa el impuesto si se ejecuta a su propietario, incluyéndolo en la nómina de deudores morosos. Si se ejecuta al ocupante del bien raíz, el crédito fiscal solo podrá hacerse efectivo en los bienes de dicho ocupante y no en el inmueble, y lo mismo sucederá en caso de ejecutarse a una persona que no tiene la calidad de deudora, como por ejemplo un propietario anterior, como sucedía en la especie: recordemos que la obligación de pagar este impuesto es una obligación propter rem, en que la persona del deudor está perfectamente determinada.

Estas consideraciones no son ociosas, puesto que la incidentista acreditó que, desde 1992, ella era la dueña exclusiva del inmueble rematado, no obstante lo cual, se ejecutó y emplazó a un ex propietario. Así las cosas, el inmueble cuyo impuesto se cobraba no pudo quedar embargado ni estuvo disponible para su remate.

5.3. Asentado el hecho de que la Tesorería solo puede ejecutar al propietario del inmueble para poder subastarlo y pagar la deuda de impuesto territorial con el producto del remate, toca ahora establecer quién ha de ser tenido por dueño del inmueble.

Rigiendo entre nosotros el régimen de posesión inscrita y al tenor de la norma del artículo 700 del Código Civil, el poseedor del inmueble será reputado su dueño mientras otro no justifique serlo; y el poseedor del inmueble es aquél que figure como dueño en el Registro Conservatorio de Propiedad, de modo que, si la Tesorería quiere ejecutar al propietario, deberá enderezar la acción de cobro en contra de quien figure como dueño en dicho Registro y no contra quien aparezca como tal en los registros de Tesorería y del Servicio de Impuestos Internos -como el rol de avalúos-, porque se trata de registros meramente administrativos que no acreditan dominio.

5.4. Según el artículo 16 de la ley 17.235, el Servicio de Impuestos Internos debe mantener al día los roles de avalúos definitivos de los inmuebles del país, utilizando, entre otras fuentes, la información que aporten los notarios, conservadores y también los propietarios de los bienes raíces. ¿Qué pasa si el dueño de un inmueble no se preocupa de actualizar esa información ante la autoridad administrativa? Esta pregunta surge a propósito de los puntos de prueba números 2 y 3 , parte final, antes mencionados, fijados por el tribunal de primer grado con miras a la resolución del incidente.

A la luz de lo dicho, y desde la perspectiva del juicio ejecutivo de cobro de contribuciones morosas, la falta de actualización de la información del dueño de un inmueble ante el Servicio de Impuestos Internos no acarrea ninguna consecuencia. En efecto, si la Tesorería quiere rematar el inmueble, debe 
ejecutar a su dueño, incluyendo en la nómina a quien figure como tal en el Registro Conservatorio de Propiedad, resultando completamente irrelevante la persona que figure como propietaria en el rol de avalúos o en algún otro registro interno de la Tesorería o del Servicio de Impuestos Internos. Puesto en otras palabras, y para efectos de la resolución del incidente de que venimos hablando, el hecho de que la solicitante no hubiera actualizado la información acerca del propietario del bien raíz ante el Servicio de Impuestos Internos, no eximía a la ejecutante de su obligación de consultar el Registro de Propiedad del Conservador de Bienes Raíces si quería ejecutar al propietario del predio, ni le daba derecho para hacer efectivo el crédito fiscal en el patrimonio de una persona ajena a la relación procesal. De lo anterior resulta que los artículos de prueba 2 y 3, parte final, resultaban superfluos para resolver el artículo de nulidad de que se trataba.

5.5. No deja de llamar la atención que el hecho de que el fallo de primer grado haya fundado su decisión en la idea de que el remate en pública subasta constituiría en realidad una expropiación y no una compraventa, y que bastaría el solo remate para que se transfiera el domino al adjudicatario. Se trata de dos errores manifiestos por cuanto, si bien se ha sostenido por algunos que la venta forzada sería en realidad una expropiación, dicha tesis no tiene ningún sentido ni sustento en nuestro ordenamiento jurídico, en que el legislador ha tomado decidido y expreso partido por la idea de que la venta forzada constituye un verdadero contrato de compraventa, según resulta de leer el artículo 671 del Código Civil $^{13}$. Cabe hacer presente, eso sí, que la Corte de Apelaciones de Santiago eliminó el considerando quinto del fallo apelado, que sustentaba la tesis de la venta forzada como expropiación, y también la idea de que bastaría la sola subasta para que se transfiera el dominio al adjudicatario.

5.6. No podemos dejar de mencionar un hecho fundamental: en este juicio especial solo tiene la calidad de ejecutado quien figure como deudor demandado en el título ejecutivo, siendo terceros ajenos a la relación procesal quienes no figuren en la nómina de deudores morosos, aun cuando tengan la calidad de deudores del impuesto.

En la especie se había ejecutado a un ex propietario del inmueble, quien no tenía a la sazón la calidad de deudor del impuesto territorial, no obstante, fue indebidamente incluido en la nómina y también notificado y requerido de pago. Este hecho impedía que se llevara a cabo la ejecución en bienes de los deudores -el propietario y el ocupante de la bien raíz-, porque eran terceros extraños al juicio y, sin embargo, no solo se remató el sitio, sino que el juez compareció en la posterior escritura de compraventa y tradición como representante del

13 Navarrete (2004), pp. 151-153. 
Algunas consideraciones en torno al juicio ejecutivo de cobro de impuesto territorial, con especial mención de la persona del ejecutado y del patrimonio en que Tesorería puede hacer efectivo el crédito fiscal. A propósito de un fallo del Juzgado de Colina y su confirmación

dueño del inmueble, suponiéndose una representación legal de la que carecía, porque su pretendido representado no había sido parte pasiva de la ejecución.

Si bien el incidente estuvo mal planteado - no había en realidad falta de emplazamiento, sino inexistencia de relación jurídico-procesal respecto del dueño del sitio adjudicado ${ }^{14}$-, el tribunal tenía la obligación de advertir que se había ejecutado a una persona distinta del dueño del inmueble, al revisar la inscripción de dominio del predio rematado y al redactar la escritura pública de adjudicación, lo que tendría que haber llevado al juez de la causa a dejar sin efecto todo lo obrado respecto de ese bien raíz, en lugar de moverlo a efectuar el traspaso de la propiedad al adjudicatario, despojando de su propiedad a una persona que no era parte del juicio, que no fue notificada ni requerida de pago, y que no tuvo oportunidad de defenderse.

5.7. Como se comprende, el plazo para reclamar de este vicio no podía contarse desde la publicación de los avisos que daban publicidad al remate, porque se trata de una actuación que no está ordenada, ni tiene la aptitud para poner en conocimiento de una persona el hecho de que va a rematarse un inmueble de su propiedad. En efecto, mediante la publicación de tales avisos solo se busca informar a los eventuales interesados, a fin de que puedan presentarse oportunamente a la subasta y hacer posturas. Los avisos tampoco resultan idóneos para emplazar al deudor, porque el emplazamiento supone que se haya dirigido efectivamente una demanda en su contra, y en la especie se había demandado ejecutivamente a una persona distinta. De todos modos, el emplazamiento implica el conocimiento efectivo de la demanda y exige también el requerimiento de pago, en obedecimiento del cual el deudor habría podido evitar el remate de su propiedad, pagando la deuda que se le requería solucionar. Lo mismo puede decirse de la inscripción conservatoria del título: se trata del medio previsto expresamente por el legislador para efectuar la tradición de los inmuebles y no de un acto jurídico procesal que permita emplazar ni informar a una persona que se va a rematar un inmueble de su propiedad, y mucho menos si el remate ya había tenido lugar, como sucedía en este caso.

Resulta interesante, Ilegados a este punto, recordar un importante fallo pronunciado por la Corte Suprema, recaído en un caso similar al que comentamos: sucedió que el Fisco arrendaba dos inmuebles a terceros, y la Tesorería inició ejecución en contra de los arrendatarios de ambos predios a fin de obtener el pago del impuesto territorial, resultando rematados y adjudicados los

\footnotetext{
14 Inexistencia de relación jurídico-procesal fue, precisamente, el fundamento que dio la Corte de Apelaciones de Concepción para anular de oficio todo lo obrado respecto de un inmueble, cuyo propietario no figuraba en la nómina de deudores morosos (Corte de Apelaciones de Concepción, rol $N^{\circ} 1.152-2013$, de 29 de octubre de 2014).
} 
inmuebles a un mismo postor. El Fisco compareció en el juicio después del remate, promoviendo y perdiendo en ambas instancias incidente de nulidad de lo obrado, por falta de emplazamiento. La Corte Suprema declaró inadmisibles los recursos de casación del Fisco, de modo que el subastador pidió al Conservador de El Loa-Calama que inscribiera la escritura de remate a su nombre; dicho Conservador se negó, alegando graves vicios en la tramitación del juicio ejecutivo de cobro de impuesto territorial. El subastador pidió al juez que ordenara a dicho Conservador practicar la inscripción requerida, solicitud que fue acogida por el tribunal. Elevado el fallo en consulta, fue revocado por la Corte de Apelaciones de Antofagasta. Conociendo de los recursos de casación interpuestos por el adjudicatario, la Corte Suprema los rechazó, dando la razón al Conservador reclamado, argumentando que el juicio de cobro de contribuciones morosas en que habían sido rematados los dos inmuebles referidos, sin que se hubiera ejecutado a su propietario, era meramente aparente, por vulneración de presupuestos de existencia del proceso; asimismo, las resoluciones dictadas en él eran también aparentes respecto del propietario, y no podían producir cosa juzgada sustancial, sino meramente aparente respecto del dueño de los inmuebles, de modo que el Conservador había obrado con apego a la ley al negarse a inscribir la escritura de adjudicación a nombre del subastador ${ }^{15}$.

Para dar la razón al propietario perjudicado, este fallo -fuera de reconocer que solo puede rematarse el inmueble que causa el impuesto si se ejecuta a su propietario- pasó por sobre otro fallo de la propia Corte Suprema, que había declarado inadmisibles los recursos de casación del Fisco, y favoreció al propietario de los inmuebles, prescindiendo del plazo legal de cinco días para promover incidentes.

\section{Conclusión}

Los fallos que comentamos resultan gravemente errados, en primer lugar, por permitir que se rematara el inmueble de una persona que no había sido ejecutada ni emplazada, y que se había visto injustamente privada de su derecho a defensa; en segundo lugar, por estimar extemporánea la interposición del incidente, al asumir que el propietario del sitio se había enterado de la existencia del juicio con la práctica de actuaciones que no resultan aptas para informar a una persona que se le subastaría un bien raíz, y mucho menos para emplazarla. Y, en tercer lugar, por no hacer uso de las facultades para actuar de oficio una vez que se acreditó que se había ejecutado a una persona que no era deudora del impuesto ni dueña del inmueble; si bien ya se había inscrito el

15 Corte Suprema, rol N 5906-2007, de 10 de diciembre de 2008. 
título a nombre del subastador, es claro que el tribunal podía y debía ordenar la cancelación de tal inscripción -la que, a la par de acto civil de tradición es también el último acto del juicio ejecutivo-, considerando que, si la falta de emplazamiento permite cancelar una inscripción conservatoria, con mayor razón exige dicha cancelación un vicio más grave, como es la inexistencia de relación jurídico-procesal respecto del propietario del inmueble rematado y adjudicado.

\section{BiBLIOGRAFíA CITADA}

Alessandri R., Arturo; Somarriva U., Manuel y Vodanovic H., Antonio (2001): Tratado de Las Obligaciones (Santiago, Editorial Jurídica de Chile), volumen I, $2^{\text {a }}$ edición.

Llambías, Jorge Joaquín (1983): Tratado de Derecho Civil. Obligaciones (Buenos Aires, Editorial Perrot), tomo I, 4ª edición actualizada.

NavarRete VileGas, Gonzalo (2004): Embargo, tercerías y realización de bienes (Santiago, Editorial Jurídica de Chile).

Rojas RetAMAL, Roberto (2001): El Impuesto Territorial, (Santiago, Editorial Jurídica Conosur Ltda.).

\section{NORMAS CITADAS}

\section{Código Tributario}

Ley $N^{0} 17.235$, sobre impuesto territorial. Diario Oficial, 24 de diciembre de 1969.

\section{JURISPRUDENCIA CITADA}

Fisco con Inmobiliaria Las Canteras Ltda. y otros (2016): Corte de Apelaciones de Santiago, 31 de mayo de 2016 (juicio ejecutivo de cobro de impuesto territorial, apelación de incidente de nulidad de lo obrado), rol № 3028-2016.

Fisco con Inmobiliaria Las Canteras Ltda. y otros (2016): Juzgado de Letras de Colina, 5 de febrero de 2016 (juicio ejecutivo de cobro de impuesto territorial, incidente de nulidad de lo obrado), rol № 1451-2013.

Fisco Tesorería Provincial de Talcahuano con Julio Martis Amigo y otros (2014): Corte de Apelaciones de Concepción (juicio ejecutivo de cobro de impuesto territorial, apelación de incidente de nulidad de lo obrado), rol $\mathrm{N}^{\circ} 1152-2013$.

Tesorería General con Caica y otros (2010): 20 Juzgado Civil de Santiago, 24 de diciembre de 2010 (juicio ejecutivo de cobro de impuesto territorial, incidente de nulidad de lo obrado), rol No 35676-2009. 
Juan Ureta Salas con Conservador de Bienes Raíces (2008): Corte Suprema, 10 de diciembre de 2008 (reclamo en contra de Conservador de Bienes Raíces), rol No 5906-2007.

Comercial Las Brujas Limitada con Fisco de Chile (2008): Corte de Apelaciones de Concepción, 10 de septiembre de 2008 (juicio ordinario de declaración de prescripción de obligaciones tributarias, apelación de sentencia definitiva), rol No 519-2005.

Servicio de Tesorerías con Errázuriz y otros (1998): $28^{\circ}$ Juzgado Civil de Santiago, 19 de enero de 1998 (juicio ejecutivo de cobro de impuesto territorial, incidente de nulidad de lo obrado), rol No 1658-1995. 